\title{
DEVELOPMENT OF INTELLIGENT AUTOMATED System for Plant Protection Product CONTROL IN ORCHARDS BASED ON FUZZY LOGIC
}

\author{
StajnKo, D., RAKUn, J., LAKOTA M., Vindiš, P. \& Berk, P.
}

Abstract: Conventional process of plant protection product (hereinafter PPP) used against diseases, fungus, insects and weeds runs with a range of spraying techniques and equipment, such as sprayers, air blasters and foggers. However, in many cases the $P P P$ residues remain in the environment and find their way into food, despite several different models to calculate the correct dosage of PPP. To overcome this problem it is necessary to integrate the tree canopy properties (the density of leaf area) in the model with intelligent automated systems, which enables controlling the amount of spray mixture in orchards. This chapter represents the development of intelligent decision-making model, which operates on the principle of fuzzy logic algorithm and generates the pulse width modulation (hereinafter PWM) signal in real-time.

Key words: PPP, fuzzy logic, electromagnetic valve, spray mixture, algorithm
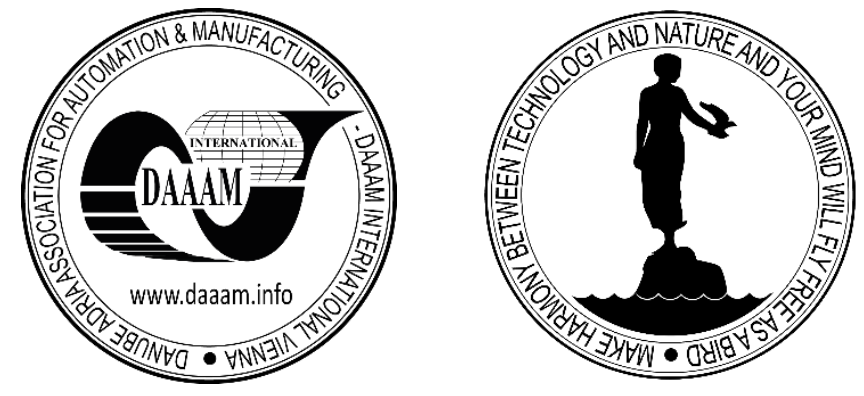

Authors' data: Full. Prof. Stajnko, D[enis]; Assist. Prof. Rakun, J[urij]; Assoc. Prof. Lakota, M[iran]; Assist. Prof. Vindis, P[eter], Senior Lecturer Berk, P[eter]; University of Maribor, Faculty of Agriculture and Life Sciences, Pivola 10, SI-2311, Hoče, Slovenia, denis.stajnko@um.si, jurij.rakun@um.si,_miran.lakota@um.si, peter.vindis@um.si, peter.berk@um.si

This Publication has to be referred as: Stajnko, D[enis]; Rakun, J[urij]; Lakota, M[iran]; Vindis, P[eter] \& Berk, P[eter] (2019). Development of Intelligent Automated System for Plant Protection Product Control in Orchards Based on Fuzzy Logic, Chapter 02 in DAAAM International Scientific Book 2019, pp.017-032, B. Katalinic (Ed.), Published by DAAAM International, ISBN 978-3-902734-24-2, ISSN 17269687, Vienna, Austria

DOI: 10.2507/daaam.scibook.2019.02 
Stajnko, D.; Rakun, J.; Lakota, M.; Vindis, P. \& Berk, P.: Development of Intellige...

\section{Introduction}

Since the end of $19^{\text {th }}$ century the plant protection products (hereinafter PPP) are used against diseases, fungus, insects and weeds that need to be eliminated for ensuring a good harvest. For treating the plants a wide range of sprayers, air blasters and foggers are used. However, the down side is that PPP residues remain find their way into the soil, groundwater, air, plants and finally into the food. Currently, sustainable agriculture is the only alternative, since the ecological agriculture, which uses less harmful chemical, cannot produce enough food for the growing population. The solution for environmental friendly PPP application represents selective and precise PPP application.

The majority of growers still use extensive out-dated expression models such as tree canopy volume, dose expression model per ha ground, Leaf Wall Area (LWA) or canopy height models. In the traditional dose expression models the dosage of PPP remains independent from the properties of each tree canopy in the orchard, thus potentially excessive dosages of PPP may appeared in the orchard, due to distinct properties of individual trees in the orchard.

From the begging of 1980s more advanced PPP application controls were studied by different authors (Ladd \& Reichard, 1980), which began to use precision control systems. Those systems operated on the principle of ultrasonic, spectral and photogrammetric principles. Based on information provided by such sensors, the sprayer's processing system detects trees, and through I/O control units and EMV adjust the dosage of PPP in ON/OFF (Doruchowski et al., 1998), discrete (Moltó et al., 2001) or continuous mode (Escola et al., 2013). In the future, the only alternative to those principles will be a continuous dosage of PPP according to the individual tree canopy in orchards.

At the current state of the art, the sprayers, positions and orientation of nozzles used for PPP application are fixed at a given height and are only partly adapted to the non-linear shape of the canopy tree over the entire height. Contrary, Osterman et al. (2013) reported on the use of an adapted prototype sprayer with adjustable 8 degrees of freedom hydraulic manipulator arms with the intention of spraying targets perpendicular to the canopy contour at a selected distance.

However, in the PPP application, it is not sufficient to measure only geometrical characteristics of each tree canopy, but also to apply the appropriate amount of PPP to the selected canopy segment selectively. In general, current sprayers with axial, centrifugal or tangential fans are unable to deliver PPP precisely to selected targets. This means that a new generation of high precision sprayers is required, which applies systems for the direction and amount of airflow. The first step towards the new technique was the development of ultrasonic measuring system supported with the intelligent system for estimating the leaf area of the tree canopy (Stajnko et al. 2013). The measured values of the leaf area density on three different canopy heights was used to spray mixture process control. The conventional dose expression model per hectare ground we upgraded to intelligent decision-making model with a fuzzy logic algorithm. The algorithm based on a dose expression model per hectare ground where the measurements of leaf area density were considered. 
Later, the LIDAR (Laser scanning) measurement were used to detect the tree canopy in precision agriculture. Two-dimensional or multi-dimensional contour data was captured through a laser scanning measurement system enabling the construction of three-dimensional point clouds (Walklate et al. 2002). By appropriate algorithms, these point clouds was used to digitally reconstruct and describe the tree canopy properties with a high level of precision (Rakun et al., 2012). The use of LIDAR has many advantages in comparison to ultrasound, because it measures objects (leaves) in any position in real time. However, in the case of a high density leaf area, the majority of the laser beams are reflected back from the outside surface of the canopy. This may cause a "shadow effect", which reduces the amount of information for the inside surface of the canopy, and it is one of the main disadvantages of the laser measurement system (Sanz Cortiella et al., 2011). To overcome this problem intelligent algorithms for PPP control is required.

In the following paragraphs a potential direction of future development of decision-making model will be represented which use a fuzzy logic system. Such algorithms enables continuous control of the PPP dosage in a range from $0 \%$ to $100 \%$ due to the dynamical connection among various types of input variables (laser beam reflection from the tree canopy, the leaf area size, the LAI index and the sprayer travel speed).

\section{Technical background of the fuzzy logic measuring system}

\subsection{Intelligent automated system prototype}

Represented intelligent automated system prototype was tested in the laboratory conditions, in which the spray dosage process and determination of the most suitable parameters for more accurate process was controlled.

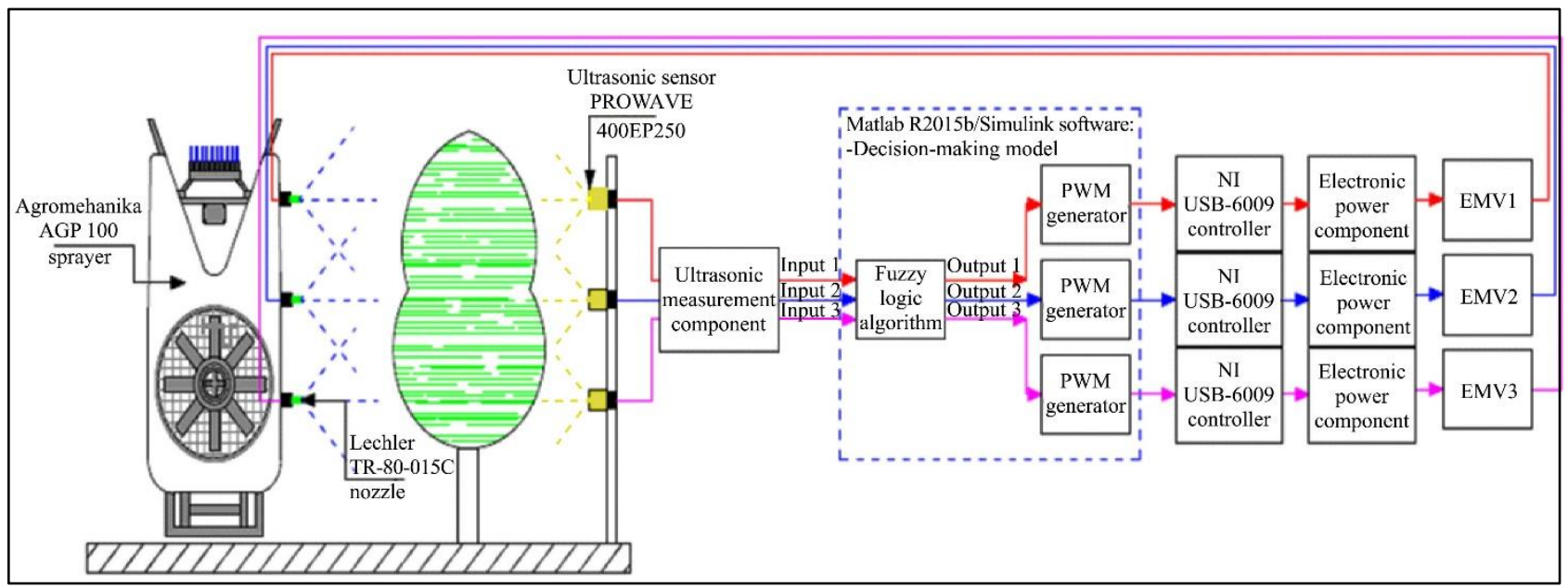

Fig. 1. The structure of the intelligent automated modular system for the PPP control application.

The entire intelligent modular system (Fig. 1) consists of the conventional axial sprayer, measuring component for data acquisition (leaf area density) based on ultrasonic sensors and control components for EMV control (spray mixture control in PWM mode). 
Stajnko, D.; Rakun, J.; Lakota, M.; Vindis, P. \& Berk, P.: Development of Intellige...

A Matlab R2015b/Simulink software with a fuzzy logic algorithm was used for simulating the passing of the sprayer over the tree canopy on the railway track. The optimal spray mixture amount was adjusted according to the distance, size and leaf area density of the tree canopy (Berk et al., 2016).

\subsection{Electromagnetic valves}

Two-position (2/2) electromagnetic valves EMV-BDA 8W ED $100 \%$ (StcValve, Palo Alto, USA) connected on a DC voltage power-supply $12 \mathrm{~V}$ were installed, which are normally closed (hereinafter NC). Typically, the EMV opens at a pressure over 0 bar. and are normally operating up to maximum working pressure of $40 \mathrm{bar}$. The pressure is directly dependent on the nominal diameter of the valve seat and electric power of the electromagnetic coil. With EMV the PPP process was able to control in real-time by using an external PWM signal, which configure the duty cycle of PWM 12 V DC signal in proportional range from $0 \%$ to $100 \%$. Based on earlier laboratory tests the optimum frequency range of the periodic opening and closing of the EMV was set to $10 \mathrm{~Hz}$ (Berk et al., 2010).

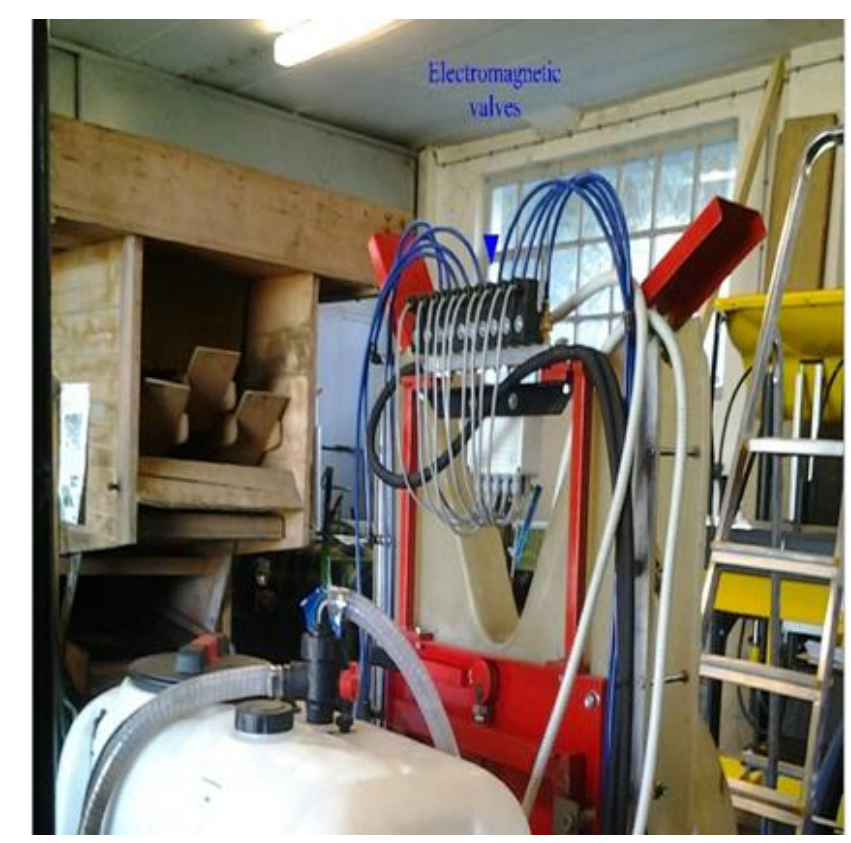

Fig. 2. 2/2 NC electromagnetic valves mounted on a conventional sprayer.

\subsection{Electronic ultrasonic measurement system}

Measurement system was installed on a conventional sprayer Agromehanika AGP 100 commercial sprayer (Agromehanika, Kranj, Slovenia) equipped with 3 nozzles on each. The ultrasonic sensors were used for the tree canopy characterization (density of leaf area) and communicated with the measurement system through the RS-232 interface.

A system was build around a LPC 1343 microcontroller and connected to the HP Compaq 6830s computer using USB and RS-232 interface. It is used to trigger the ultrasonic sensors, read their outputs and send it as a whole to the computer via RS232 interface. 


\subsection{Automation controller}

A NI USB-6009 controller was used, because it is configured for two analogue output channels, which were used for activating the power semiconductor elements for controlling EMVs in the PWM mode, and one physical digital output channel (digital output P0.2), for actuating a semiconductor power element. The programming language of the NI USB-6009 was Matlab R2015b (MathWorks, Natick, USA), a graphical language by means of which we write a decision-making model based on fuzzy logic algorithm for the PPP process control.

\subsection{Spraying nozzles}

The sprayer prototype was equipped with double membrane nozzles TR-80-015C (Lechler $\mathrm{GmbH}$, Metzingen, Germany), that operates without air support. The operating pressure of the nozzles 10 bar was selected. During the experiment, we recorded the nozzle flow rate $\left(\mathrm{Lmin}^{-1}\right)$ at different frequency of closing and opening the EMV. The assessment quality of spraying mixture deposit was detected on WSP (water sensitive paper) by using the image analyser Optomax (Optomax, Hollis City, NH USA). By performing the droplets analysis, the operation accuracy of intelligent automated system was assessed for intelligent PPP control and compared with conventional spraying system.

\subsection{Hydraulic circuit}

Hydraulic circuit of sprayer prototype are comprised of the following components: supporting structure with a chemically resistant polyester tank and pour sieve, pump, a pressure and flow rate regulator. The hydraulic circuit enabled to proceed the amount of PPP in conventional as well as automated spraying mode, (Fig. 3). In the conventional PPP application process all EMV were activated at once so the entire spraying boom was opened $100 \%$. Contrary, in the automated PPP application the EMVs were controlled with a PWM signal, which was generated through the automated controller.

\subsection{Sprayer prototype operation}

Automated controller was connected to the electronic power unit. Automated controller was running by software program designed in a Matlab R2015b and monitored via a laptop HP Compaq 6830s (Berk et al. 2014). We made our own user interface, which guided both modes by starting and interrupting the software program and measurement signal acquisition.

In the case of the conventional PPP mode, a $5 \mathrm{~V}$ DC control signal was sent to each three controller outputs, providing each EMV to be a fully opened. In the automated mode, the control PWM signal was sent to the EMV according to the leaf area density i.e. the presence of the tree canopy at a given specific distance from the ultrasonic sensors.

The amount of PPP (spray liquid) for three different canopy heights was calculated on the basis of the ultrasonic echo signals from the tree canopy, as represented in Eq. (1). 
Stajnko, D.; Rakun, J.; Lakota, M.; Vindis, P. \& Berk, P.: Development of Intellige...

$$
T P=\frac{1}{S R \cdot v}
$$

where $T P$ is the time period of ultrasonic echo signals intensity capturing (s); $S R$ is the sampling resolution (samples $\mathrm{m}^{-1}$ ), in our 20 samples $\mathrm{m}^{-1}$ (Stajnko et al., 2011); $v$ is the simulated travel speed of the prototype $\left(\mathrm{ms}^{-1}\right)$.

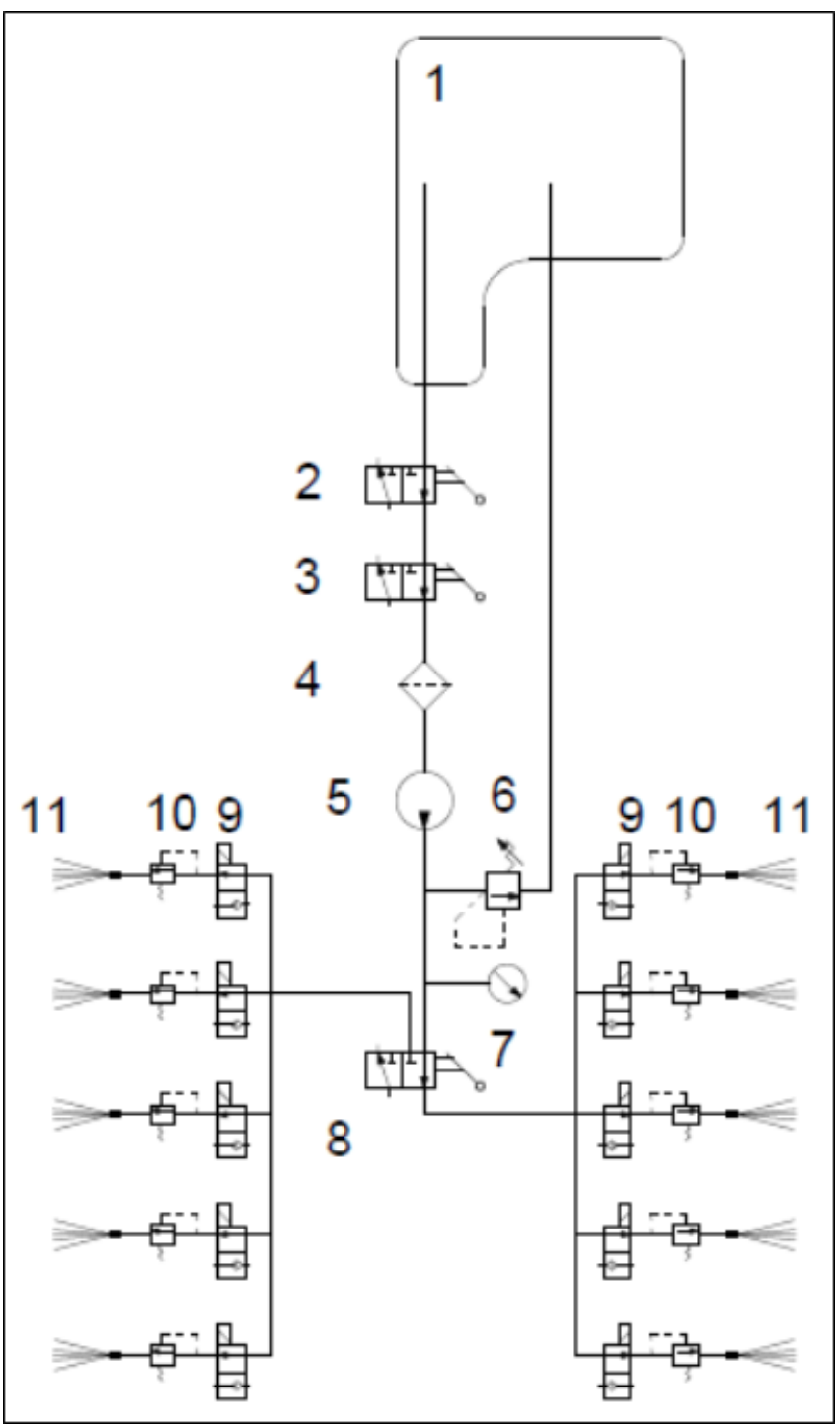

Fig. 3. Diagram of the hydraulic circuit of the sprayer prototype showing the implementation and the required components: tank (1), distributors 1, 2 and 3 (2, 3 and 8 ), filter (4), pump (5), pressure and flow rate regulator (6), pressure gauge (7), 2/2 electromagnetic valves (9), antidrip valves (10), LECHLER nozzles (11).

The actuation process control of EMV included also time delay, which depended on distances between the ultrasonic measurement system, mounted on a steel console and nozzles. The amount of liquid was activated relative to the same heights of ultrasonic sensors and nozzles, where sensors and nozzles was placed on the same distance $(0.3 \mathrm{~m})$ from the tree canopy. Relative to the same heights and distances the best possible amount of liquid was achieved for each of three heights. 


\subsection{Decision-making model for the PPP process}

The decision-making model based on electronic measurement of leaf area density and a fuzzy logic algorithm for EMV control in the PWM mode. The main task of the decision-making model was to control the amount of liquid at a constant sprayer speed and constant distance from the canopy. The measurements from the ultrasonic system served to generate the correct time of EMV to be opened. Application process itself has a non-linear static characteristic, so the fuzzy logic algorithm was used.

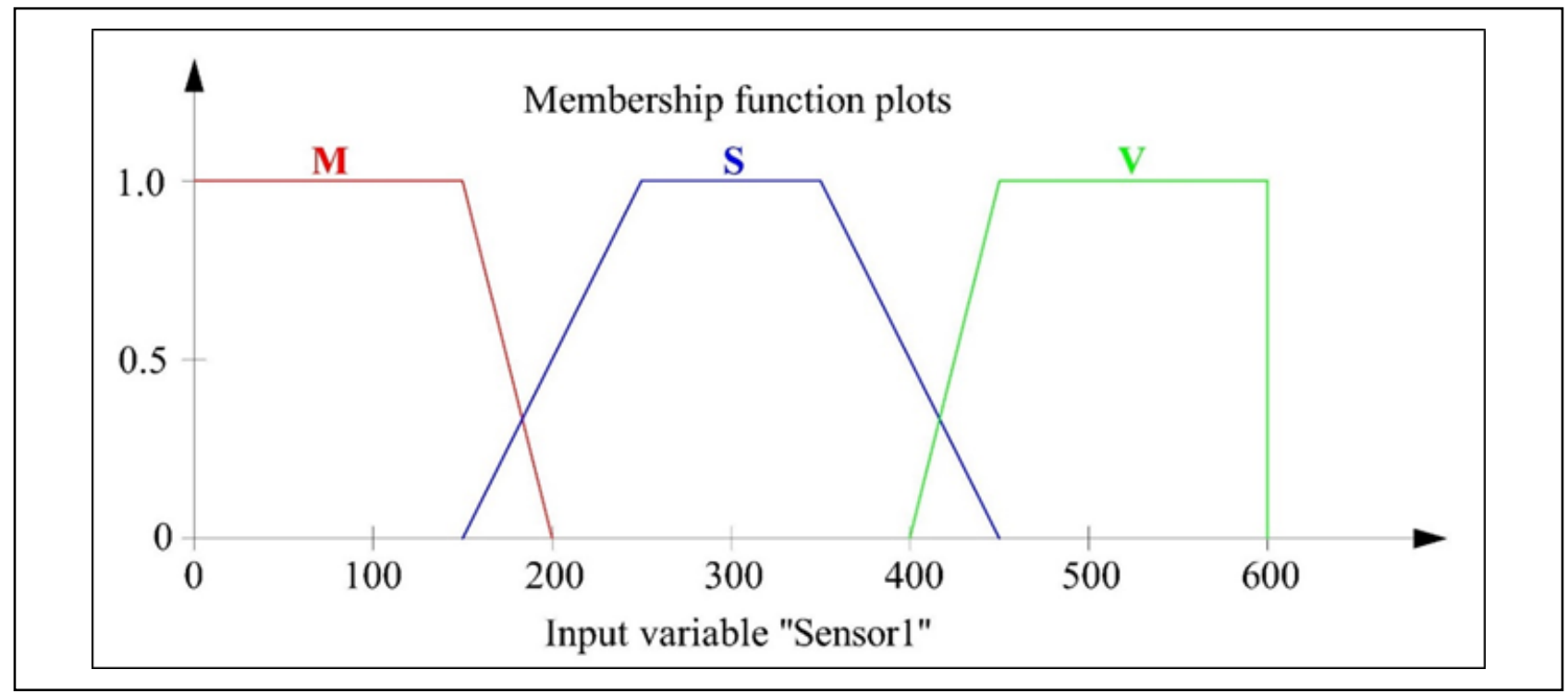

Fig. 4. Membership functions for input variable - Sensor 1.

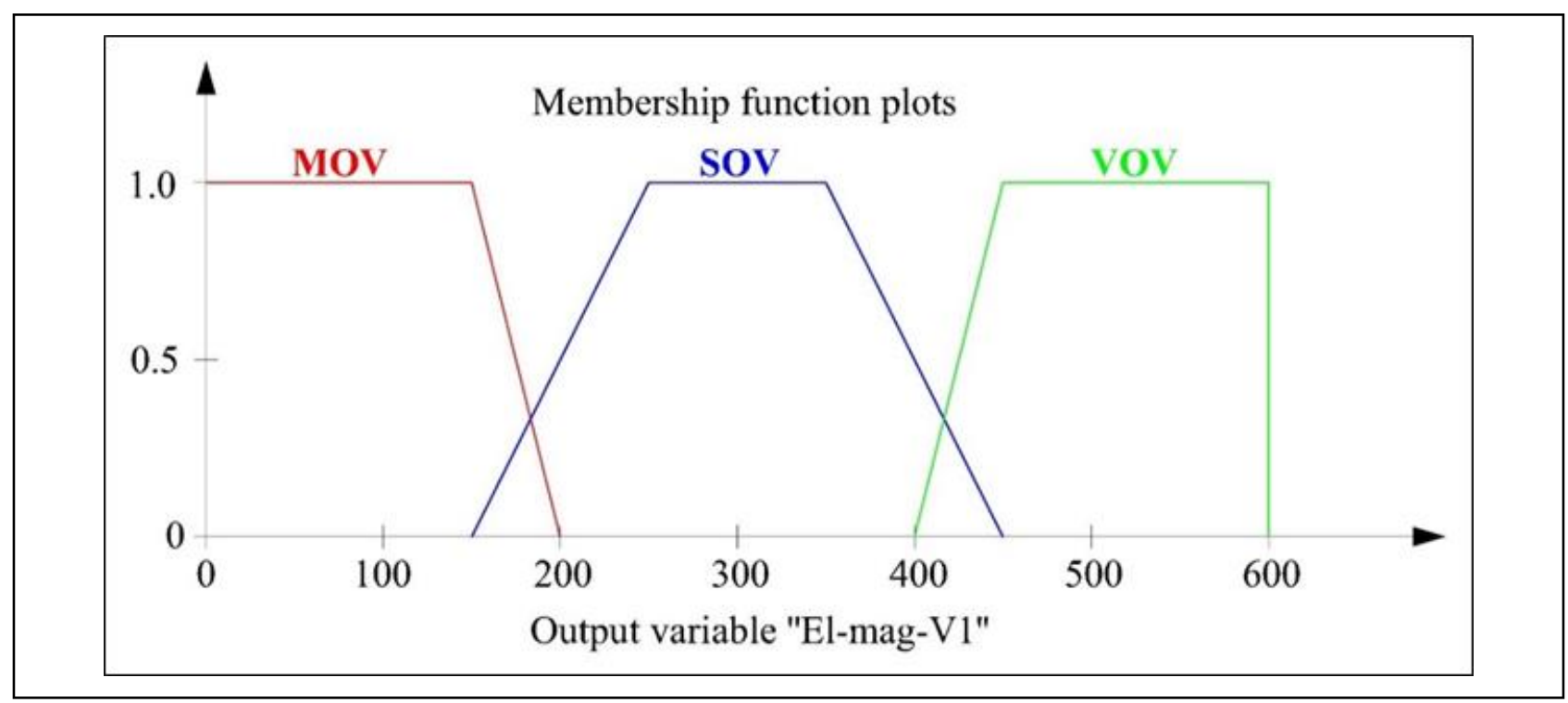

Fig. 5. Membership functions for output language variable - El-mag-V1.

It depends on the rules and membership functions for input and output variables. Input variables (Sensor1, Sensor2, Sensor3) are represented by ultrasonic measurement system (Stajnko et al., 2013) and the output (El-mag-V1, El-mag-V2, El-mag-V3) represented variable coefficients. The optimization procedure of the decision-making model started with fuzzification (Mamdani et al., 1984) of three input and three output variables. 
Stajnko, D.; Rakun, J.; Lakota, M.; Vindis, P. \& Berk, P.: Development of Intellige...

For our case a trapezoid shaped membership function was used with the following thresholds to close or open the EMV (Figs. 5 and 6). They were defined separately in an interval between $[0,600]$, as follows:

- input of Sensor 1 and output for El-mag-V1 variable: [0 0150 200].

- input of Sensor 2 and output for El-mag-V2 variable: [150 250350 450].

- input of Sensor 3 and output for El-mag-V3 variable: [400 450600600 ].

The membership functions are described by language variables from Tab. 1 .

\begin{tabular}{|c|c|}
\hline Language variables & Description of language variables \\
\hline $\mathrm{M}$ & Low \\
\hline $\mathrm{S}$ & Middle \\
\hline $\mathrm{V}$ & High \\
\hline MOV & Partly open valve \\
\hline SOV & Half open valve \\
\hline VOV & Fully open valve \\
\hline
\end{tabular}

Tab. 1 Input and output language variables with descriptions.

After the fuzzification procedure of the input and output variables, the procedure interference were realised with the help of EMV control in PWM mode rules. The total number of rules is defined by Eq. (2):

$$
N=p^{m}=3^{4}=81
$$

where $m$ represents the number of input language variables and $p$ the number of language variable levels.

Setting the rules enabled controlling of the EMV corresponds to the variable coefficient. In our case, for each EMV a sharp value (variable coefficient) was calculated as the output of fuzzy logic algorithm. In the last defuzzification procedure variable coefficient were calculated for controlling EMV. On this way, a duty cycle of PWM signal in a range from $0 \%$ do $100 \%$ was generated, which consequently controlled the amount of liquid through the EM liquid according to Eq. 3:

$$
q=V_{C} \cdot\left(\frac{N F R \cdot 600}{a \cdot v}\right)
$$

where $q$ is the amount to be sprayed in particular tree canopy height $\left(\mathrm{Lmin}^{-1}\right) ; N F R$ is the nozzle flow rate $\left(\mathrm{Lmin}^{-1}\right) ; 600$ is the factor needed to convert different units; $a$ is a working width $(\mathrm{m})$, where in experiment decided that one side of the prototype sprayer to be operational and working width was defined by value $0.3 \mathrm{~m}$; 
$v$ is the simulated travel speed of sprayer (kmh-1); $V C$ is the variable coefficient produced by fuzzy logic algorithm (relative values from 0 to 1 ).

The entire fuzzy logic algorithm was optimized by adjusting the stability, robustness, quality and with the response of the membership functions language variable values, their shape and rules. The fuzzy logic algorithm was included in the final stage of decision-making model, where dynamic properties were taken into account.

The model was build using the Matlab R2015b/Simulink environment to synthesize the process of liquid application. The block diagram of a fuzzy logic algorithm is depicted in Fig. 6, in which one can see three sensors, fuzzy logic controller, pulse width mode generator, data type converter, zero order hold and three digital outputs (Berk et al., 2012).

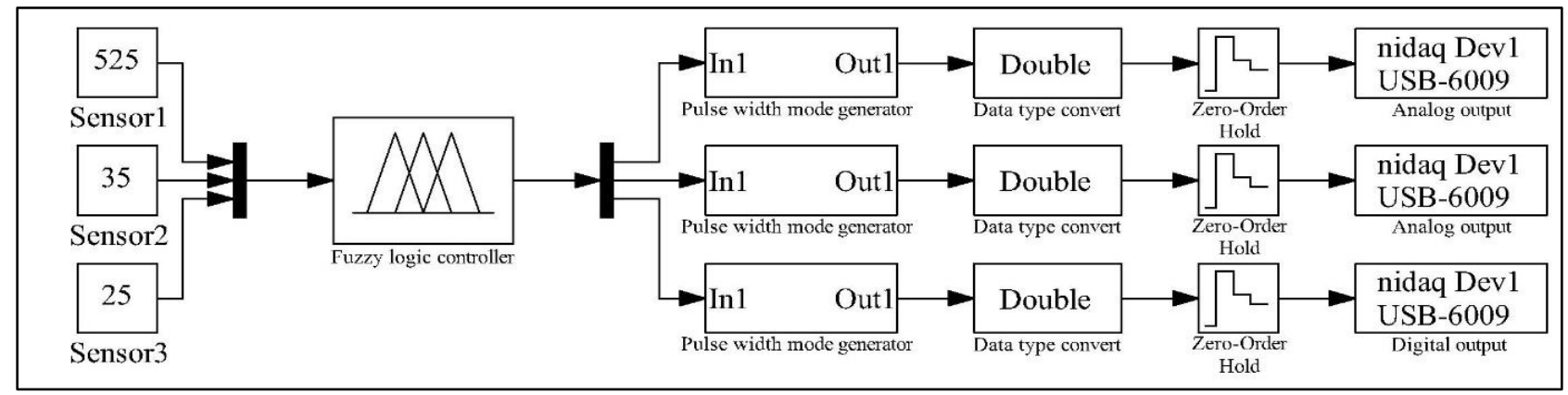

Fig. 6. Block diagram of a fuzzy logic algorithm developed in Matlab R2015b/Simulink.

Finally, a real time liquid application process was created (Fig. 7.), which consisted of separate blocks, subsystems and hardware units. The model also includes the drivers for NI-USB 6009 control component, which was used to set the analogue/digital outputs and generated the PWM signal that controls the EMV and the amount of liquid.

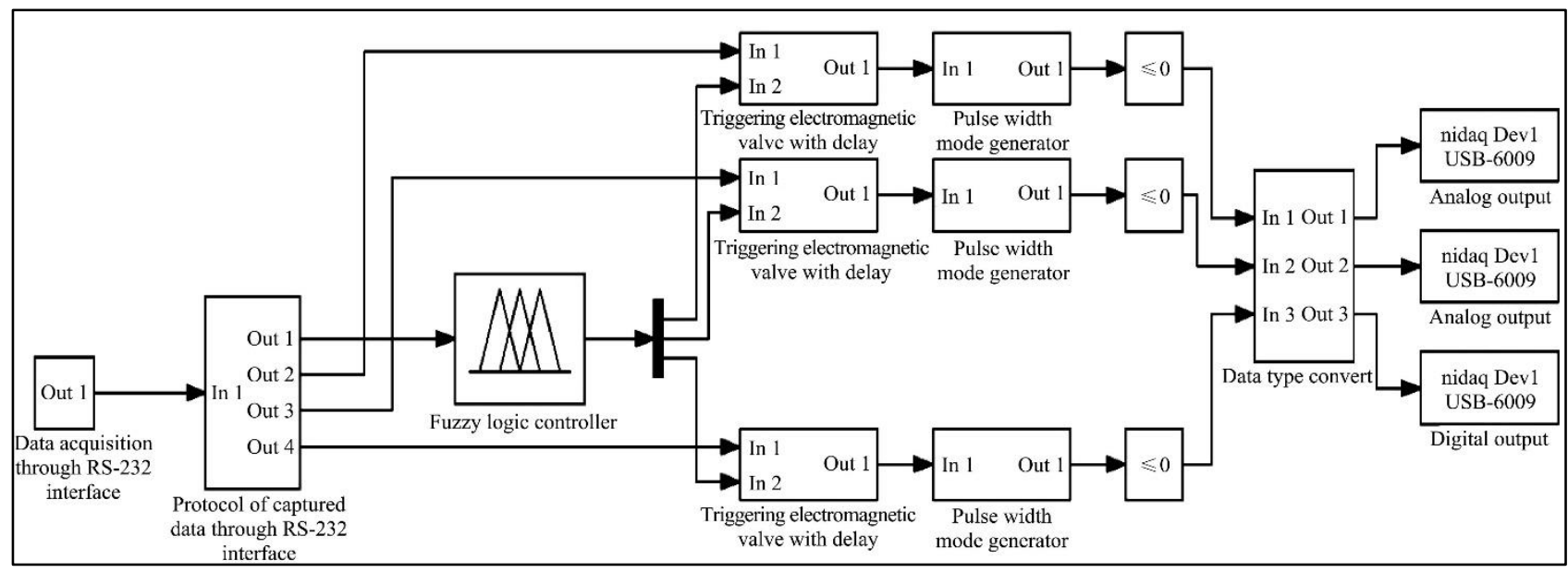

Fig. 7. Block diagram algorithm for real-time liquid application process control developed in Matlab R2015b/Simulink. 
Stajnko, D.; Rakun, J.; Lakota, M.; Vindis, P. \& Berk, P.: Development of Intellige...

\section{Laboratory test experiments}

\subsection{Synchronization time of liquid application process control}

One of the most important factors in the real-time PPP control represents synchronization time that depends on the frequency of processing and recording the ultrasonic signal, and actuation time delay. When one of the ultrasonic sensors detected the ultrasonic echo signal and when the value of the echo signal exceed a minimum threshold value of leaf area density the real-time process is triggered $(\mathrm{ON})$. The measuring process was terminated (OFF), when the value of the echo signal is smaller than the minimum threshold value. Software time between ON and OFF was used for calculating the width of the tree canopy needed to determine the average value of leaf area density. This is used for including time delay in the actuation process control of EMV Actuation time delay depended on the relative position between the tree canopy and the nozzles.

\subsection{Sprayer liquid amount control}

For controlling the amount of liquid deliver by a sprayer, it was necessary to determine the frequency range of generated PWM signal and the maximum frequency at which EMV can normally operate. The EMV actuation was tested under four different scenarios at 10 bar pressure; (1) fully opened EMV, (2) the period of the PWM signal for EMV control set at $1 \mathrm{~Hz}$, (3) the period of the PWM signal for EMV control set at $5 \mathrm{~Hz}$, and (4) the period of the PWM signal for EMV control set at $10 \mathrm{~Hz}$. Consequently, different generated shapes (duty cycles) of PWM were applied providing the widest spray liquid amount in the range from $0 \%$ to $100 \%$.

\subsection{Laboratory testing of EMV and nozzle}

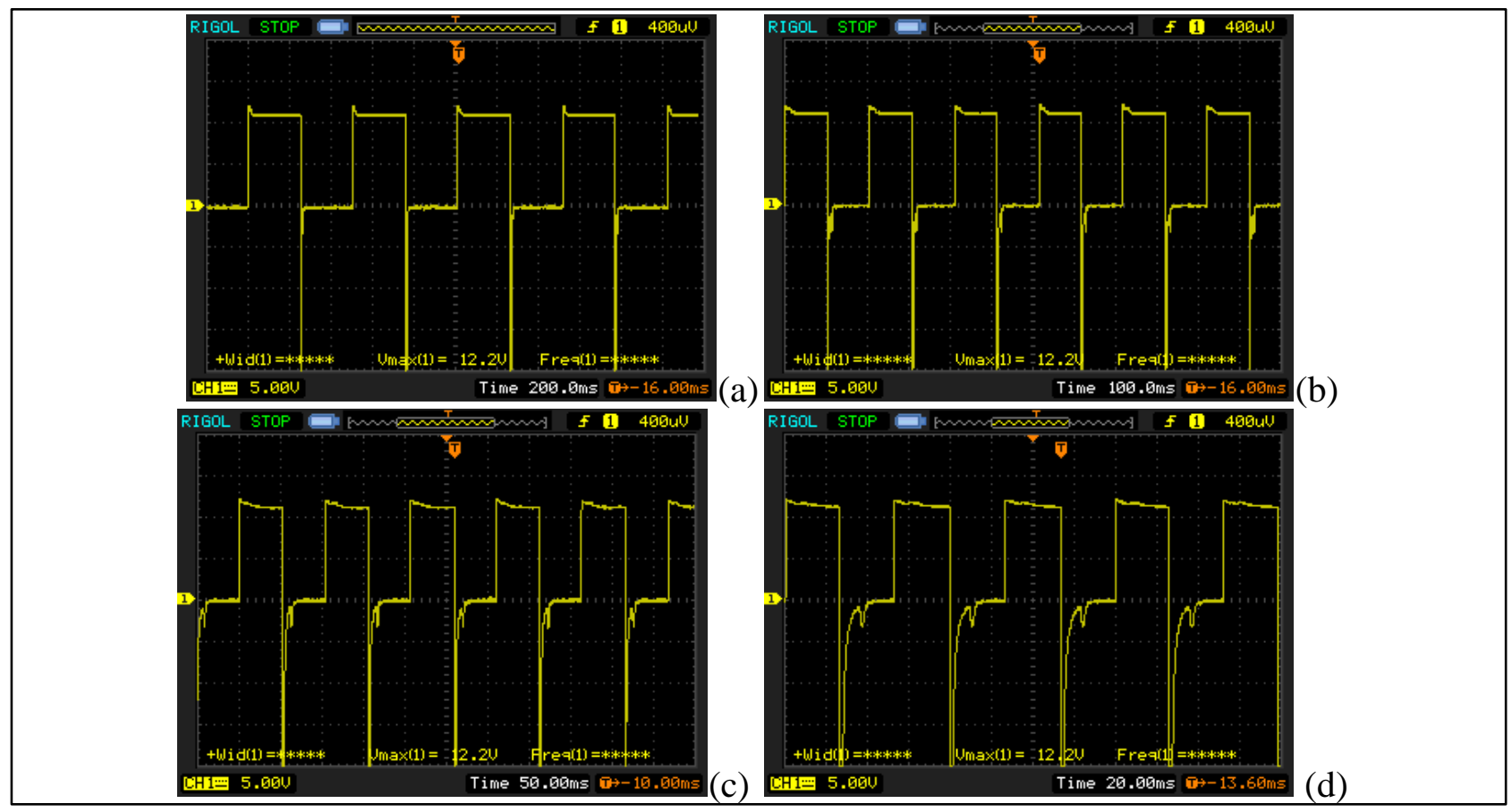

Fig. 8. Opening/closing the EMV at $1.92 \mathrm{~Hz}, 12 \mathrm{~V} \mathrm{DC} \mathrm{(a),} \mathrm{at} 5 \mathrm{~Hz}, 12 \mathrm{~V} \mathrm{DC} \mathrm{(b),} \mathrm{at} 5$ $\mathrm{Hz}, 12 \mathrm{~V}(\mathrm{c})$ and at $19.23 \mathrm{~Hz}, 12 \mathrm{~V} \mathrm{DC}$. 
Firstly, PMV mode for controlling EMV was calibrated to determine the opening/closing frequency of EMV normal. Later, the frequency of the periodic opening/closing EMV was set from $1 \mathrm{~Hz}$ to $19.23 \mathrm{~Hz}$ to ensure precise control of EMV, as shown in Fig. 8. PWM signal for EMV control were recorded using a digital oscilloscope RIGOL DS1102CA (Rigol Technologies EU, Puchheim, Germany).

As seen, at $19.23 \mathrm{~Hz}$ (Fig. 8c) the quality of the opening/closing of EMV cannot be guaranteed, since excessive delay in closing appears. The LECHLER TR-80-015C nozzle were tested on different fluid flow rate. The nozzle intended to dissipate a fluid flow in the stream with a specific droplet spectrum to ensure equal droplets deposition on the tree canopy. Experiments with 10 bar pressure showed linear flow rate through the nozzle rising according to the frequency of opening/closing EMV. By using the linear relationship of two variables (frequency, nozzle flow rate) continuous control of automated PPP was enabled.

\subsection{Laboratory field validation trials of ultrasonic measurement system}

The ultrasonic measuring system was calibrated with three ultrasonic sensors placed $0.3 \mathrm{~m}$ from the tree canopy using a $2.2 \mathrm{~m}$ high apple tree canopy at phenological stage BBCH 69. Prototype sprayer speed $\left(1 \mathrm{~ms}^{-1}\right)$ was simulated by using composite testing trail (Fig. 9).

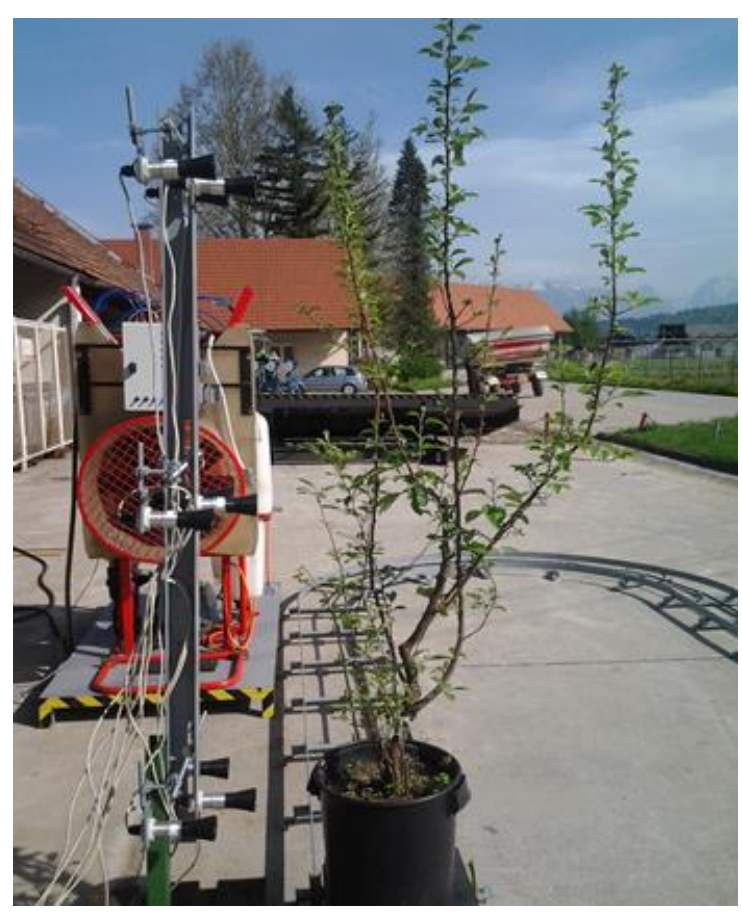

Fig. 9. Laboratory experimental setup used to test the liquid application process.

At the first height ( $0.8 \mathrm{~m}$ from ground) the intensity of the reflected echo signal was measured in the lower part of the tree canopy; the second height was set $1.33 \mathrm{~m}$ from ground for measuring the intensity of the medium part of the tree canopy. The $1.86 \mathrm{~m}$ height from the ground was used for measuring the intensity of reflected echo signal from the upper part of the tree canopy. 
Stajnko, D.; Rakun, J.; Lakota, M.; Vindis, P. \& Berk, P.: Development of Intellige...

The intensity of the reflected signals from the canopy and correct functioning of measurement system is shown in Fig. 10, in which measurement system simulated a six fold repetition of the tree canopy crossings on the testing trail.

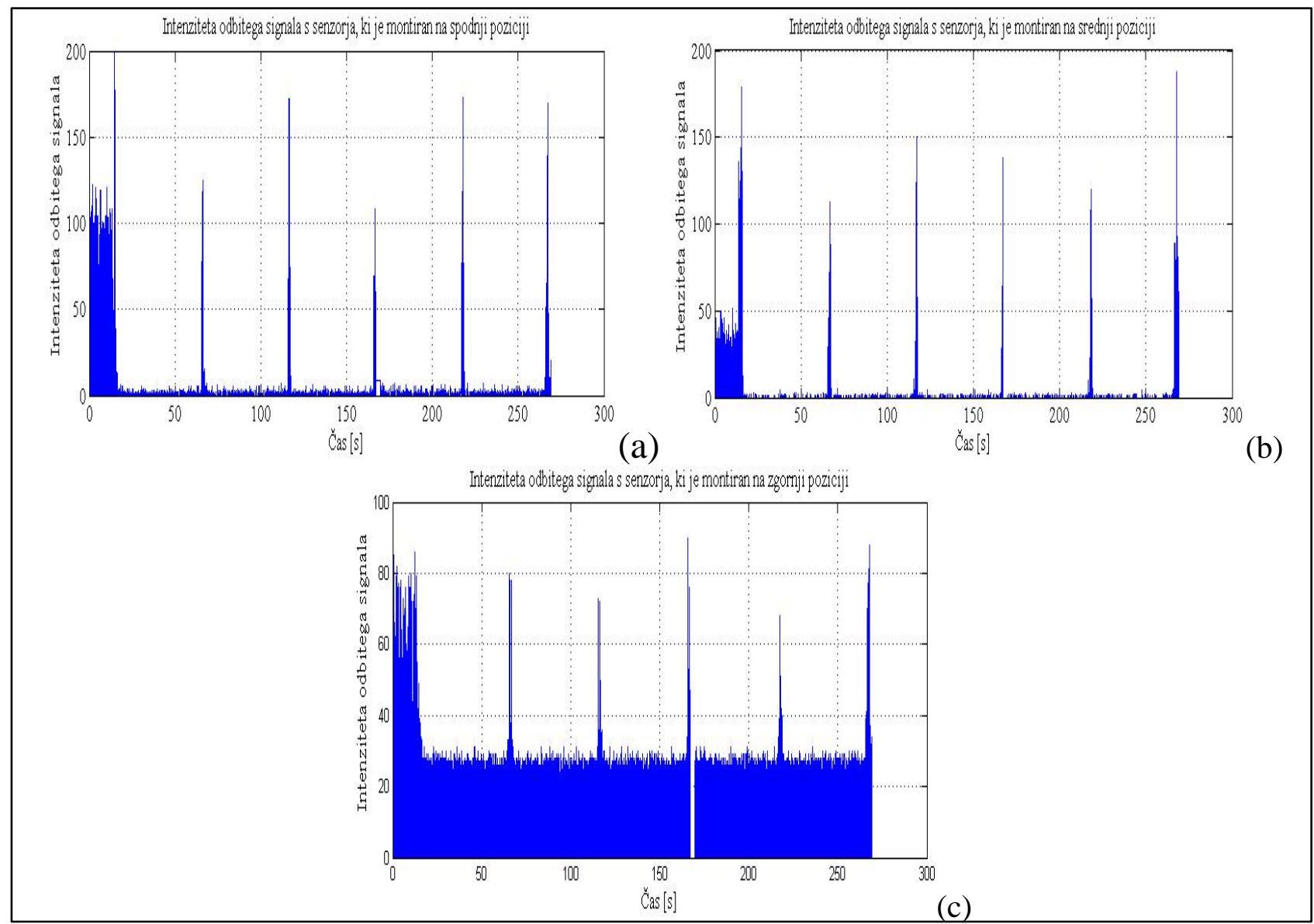

Fig. 10. The intensity of the reflected echo signal at lower (a), middle (b) and top part of the tree canopy (c) during six tree crossings

\subsection{Operating mode of decision-making model}

Operating mode of decision-making model based on fuzzy logic algorithm is optimized with Matlab R2015a/FIS components FIS Editor, Membership Function Editor, Rule Editor, Rule Viewer and Surface Viewer.

The example of rule viewer is represented in Fig. 11 showing fuzzy diagrams of membership functions in the field of operating point. For the diagnosis of active control rules and determining different shapes of membership functions is used, influencing the final calculation of fuzzy logic algorithm output value $\left(V_{C}\right)$. Contrary, a Surface viewer (Fig. 12), shows fuzzy logic algorithm output values, which depended on different sets of input variables values defined in Tab. 1 (Chapter 2.1). Different sets were defined separately in the intervals between 0 and 600 for each input sensor and output for each EMV separately. On this way the decision-making model responds most accurately on the different structure of each tree canopy shape individually, so the negative drif into the environment is reduced to the minimum level as possible. 


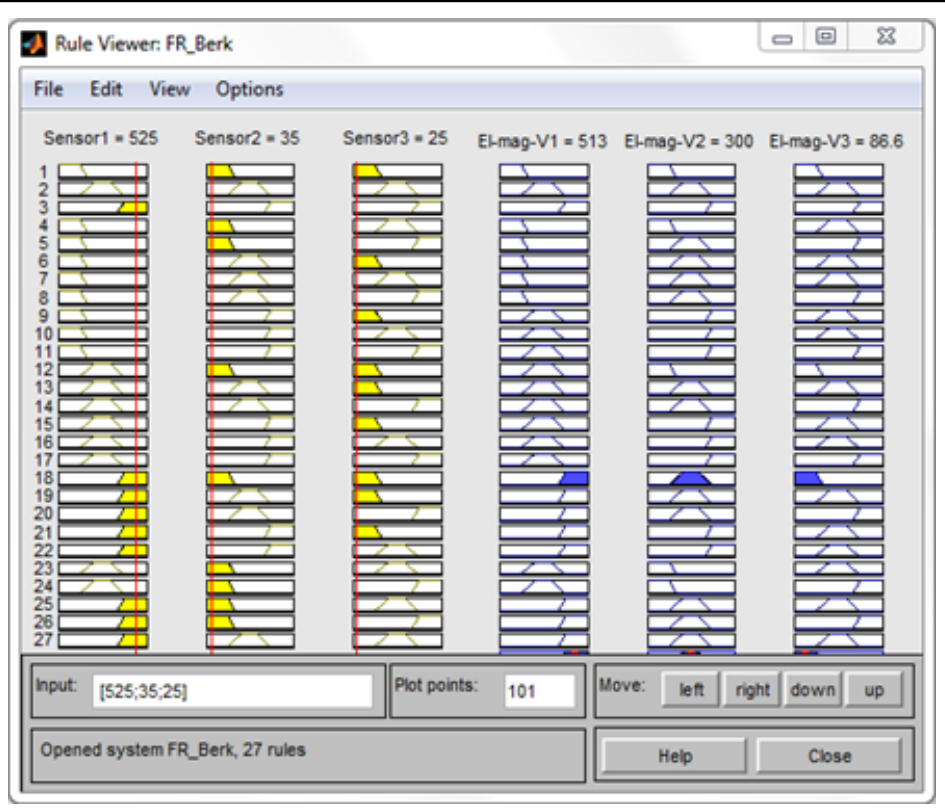

Fig. 11. Active control rules of fuzzy logic algorithm displayed in Matlab R2015a/FIS component Rule Viewer.

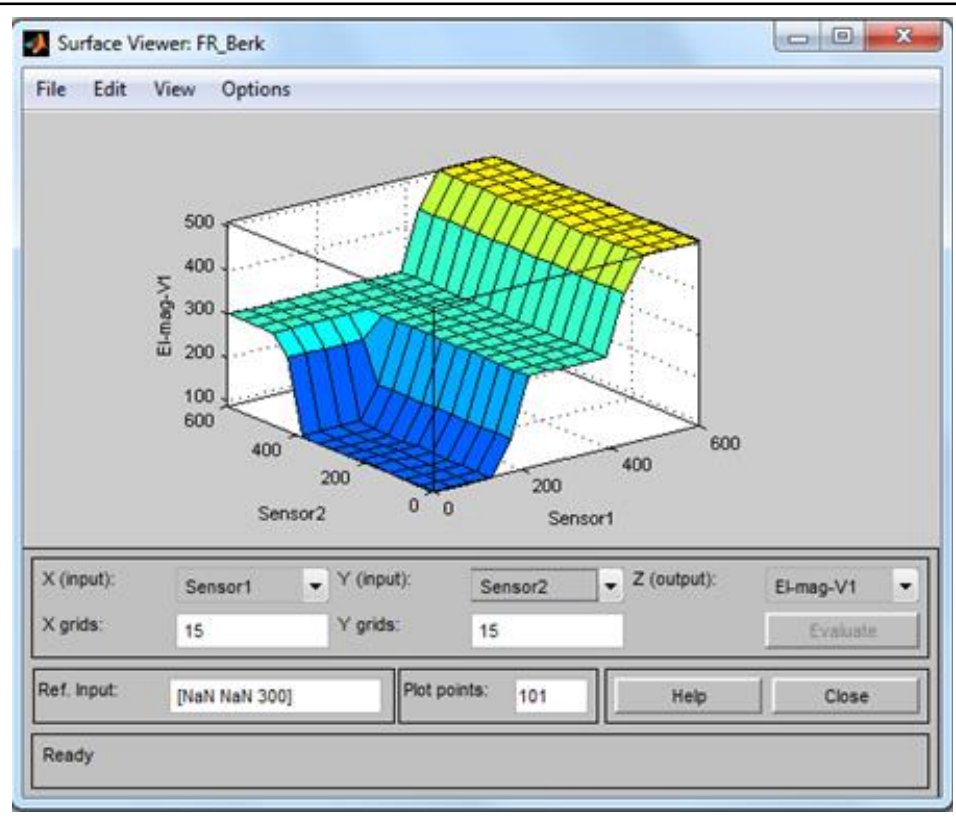

Fig. 12. Nonlinear characteristics of fuzzy logic algorithm displayed in Matlab R2015a/FIS component Surface Viewer.

Before starting the experiment, the fuzzy logic algorithm was optimized, as shown by the characteristic PMV signals figures represented in Fig. 13. Different figures demonstrate the principle of fuzzy logic algorithm operation in the case of high value intensity of the reflected echo signal from tree different tree canopy segments sent as input to the decision-making model. The first output generated a PWM signal with $85.5 \%$ duty cycle fraction of one period (Fig 13a). In the case of smaller intensity of reflected echo signal, a PWM signal with $50.0 \%$ duty cycle fraction was sent to EMV (Fig. 13b) and in the case of smallest echo signal only a PWM signal with 14.43 $\%$ duty cycle fraction was generated. 
Stajnko, D.; Rakun, J.; Lakota, M.; Vindis, P. \& Berk, P.: Development of Intellige...
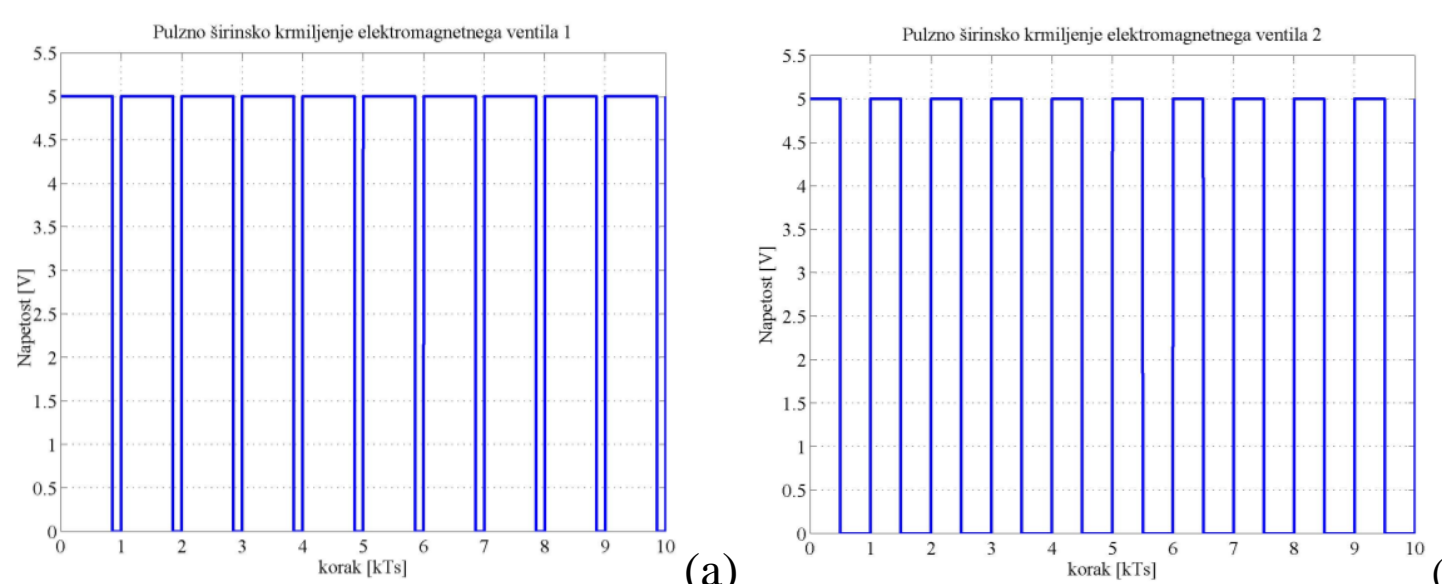

(a)

(b)

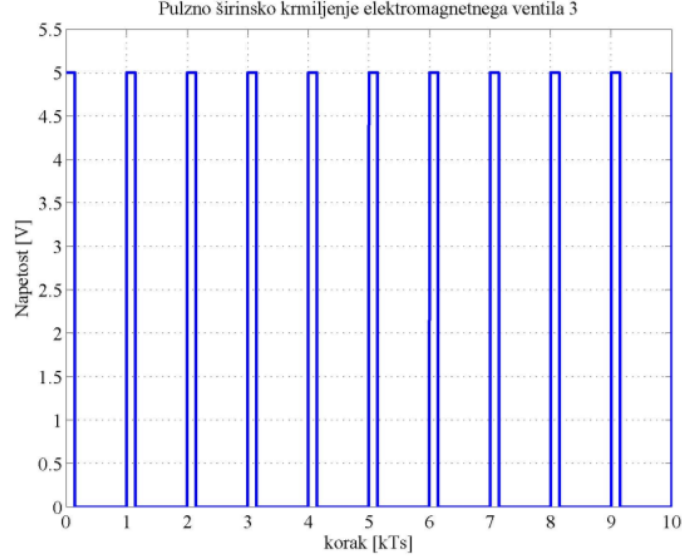

(c)

Fig. 13. The form of PWM signal at the first (a), second (b) and third height (c) generated by a decision-making model for controlling EMVs.

\subsection{Laboratory field validation trials}

For testing the real-time automated sprayer prototype, we investigated the effect of different PWM signals affect to the amount of liquid on WSP (Water Sensitive Paper) placed on six passions (inside P1, outside P2, top P3, middle P4 and bottom P5) of the tree canopy). We evaluated the coverage and the number of droplets of liquid in two different modes (automated and conventional). In an automated mode, we performed three tests; in the first a controlled duty cycle fraction by the period of the PWM signal was set at $1 \mathrm{~Hz}$, in the second $5 \mathrm{~Hz}$ and the third at $10 \mathrm{~Hz}$. In conventional mode, we performed one experiment with EMV fully opened.

The coverage of droplets on WSP per $1 \mathrm{~cm}^{2}$ was the best in the duty cycle fraction by the period, when the PWM signal was set at $10 \mathrm{~Hz}$, In this test the most uniform distribution of drops was detected; 103 drops per $\mathrm{cm}^{2}$ - location P1, 148 drops per $\mathrm{cm}^{2}$ - location $\mathrm{P} 2,78$ drops per $\mathrm{cm}^{2}$ - location P3, 69 drops per $\mathrm{cm}^{2}$ - location P4 and 134 drops per $\mathrm{cm}^{2}$ - location P5.

\section{Conclusion}

The development of decision-making model based on fuzzy logic algorithm represents accurate and intelligent tool for guiding PPP application in real-time. 
Many advantages over the conventional mode were proved in practical experiments such as the possibility of including personal knowledge about specific problems in PPP application (development of vegetation, leaf density) in particular orchards and transferring them into the decision-making process. On that way, contrary to the current on/off models, fuzzy logic algorithm enables moving the PPP application closer to the human way of thinking. Generally, this reduces the dosage of PPP per area in orchards, so fewer PPP is sprayed on the tree canopy and less drift of the PPP polluted the environment. Practical experiments showed the most optimal liquid coverage by using EMV at $10 \mathrm{~Hz}$. In this case, the shape of the droplets is optimal and the coverage of liquid is ideal, varying between $4.49 \%$ and $15.02 \%$. Contrary, at $1 \mathrm{~Hz}$ and $5 \mathrm{~Hz}$ EMV reacted slowly, with one or five open/close intervals in particular tree distance.

A logical improvement to the decision-making model would be to include more variations influencing the opening time of EMV. This would lead to more input/output variables, additional membership functions and rules. One way could be the integration of lookup table to prepare the responses of the fuzzy logic algorithm based on different input combinations from different sensors. This would certainly speed up the system due to fewer computations.

\section{Acknowledgements}

This chapter was partly created as a result of CRP project V4-1815 entitled "Reducing of draught stress and increasing of soil fertility by introducing conservation (conservation) soil tillage into sustainable agriculture «. The authors acknowledge the Slovenian Research Agency and the Ministry of Agriculture, Forestry and Food of the Republic of Slovenia for granting the project.

\section{References}

Berk, P.; Stajnko, D.; Lakota, M. \& Belšak, A. (2016). Three-dimensional reconstruction of tree canopy for assessment of leafs. In: DAAAM International scientific book 2016, Katalinic, B. (Ed.), pp. 59-68, ISSN 1726-9687, Vienna: DAAAM International Vienna.

Berk, P.; Rakun, J.; Vindis, P.; Lakota, M.; Stajnko, D. \&, Belsak, A. (2014). System for continuous control of the plant protection product. In: DAAAM International scientific book 2014, Katalinic, B. (Ed.), pp. 197-206, ISSN 1726-9687, Vienna: DAAAM International Vienna.

Berk, P.; Lakota, M.; Stajnko, D.; Vindiš, P.; Ocepek, M. \&, Rakun, J. (2012). Teleoperation of servodrive speed control using a Matlab/Simulink. In: DAAAM International scientific book 2012, Katalinic, B. (Ed.), pp. 315-326, ISSN 1726-9687. Vienna: DAAAM International Vienna.

Berk, P.; Rakun, J.; Vindiš, P.; Stajnko, D. \& Lakota, M. (2010). Temperature loop structure with fuzzy and classical controllers. In: DAAAM International scientific book 2010, Katalinic, B. (Ed.), pp. 117-128, ISSN 1726-9687, Vienna: DAAAM International Vienna. 
Stajnko, D.; Rakun, J.; Lakota, M.; Vindis, P. \& Berk, P.: Development of Intellige...

Doruchowski, G.; Jaeken, P. \& Holownicki, R. (1998). Target detection as a tool of selective spray application on trees and weeds in orchards. SPIE Conference on Precision Agriculture and Biological Quality Boston. Proc. SPIE 3543, ISSN: 19463251, pp. 290-301.

Escolà, A.; Rosell-Polo, J.R.; Planas, S.; Gil, E.; Pomar, J.; Camp, F.; Llorens, J. \& Solanelles, F. (2013). Variable rate sprayer. Part 1 - Orchard prototype: Design, implementation and validation. Comput. Electron. Agric., ISSN 1872-7107, 95, 122135.

Ladd, T.L. \& Reichard, D.L. (1980). Photoelectrically-operated intermittent sprayers for insecticidal control of horticultural pests. J. Econom. Entom., ISSN 0022-0493, 73, 525- 528.

Mamdani, E.H.; Ostergaard, J.J. \& Lembesis, E. (1984). Use of logic for implementing rule-based control of industrial processes. TIMS studies in the management sciences. North Holland, Amsterdam, New York, Oxford, ISSN 0378-3766, 20, pp. 429-445.

Moltó, E.; Martin, B. \& Gutiérrez, A. (2001). Pesticide loss reduction by automatic adaptation of spraying on globular trees. J. Agric. Eng. Res., ISSN 1095-9246, 78, 3541.

Osterman, A.; Godesa, T.; Hocevar, M.; Sirok, B. \& Stopar, M. (2013). Real-time positioning algorithm for variable-geometry air-assisted orchard sprayer. Comput. Electron. Agric., ISSN 1872-7107, 98, 175-182.

Rakun, J.; Berk, P.; Stajnko, D.; Ocepek, M. \& Lakota, M. (2012). Digital image processing approach fingerprint authentication. In: DAAAM International scientific book 2012, Katalinić, Branko (Ed.), pp. 517-526, ISSN 1726-9687, Vienna: DAAAM International Vienna.

Sanz Cortiella, R.; Llorens Calveras, J.; Escolà, A.; Arnó Satorra, J.; Ribes Dasi, M.; Masip Vilalta, J.; Camp, F.; Gràcia Aguilà, F.J.; Solanelles Batlle, F.; Planas de Martí, S.; Pallejà Cabrè, T.; Palacín Roca, J.; Gregorio López, E.; Del Moral Martínez, I. \& Rosell, P., (2011). Innovative LIDAR 3D dynamic measurement system to estimate fruit-tree leaf area. Sensors, ISSN 1424-8220, 11, 5769-5791.

Stajnko, D.; Berk, P.; Lesnik, M.; Jejcic, V.; Lakota, M.; Strancar, A.; Hocevar, M. \& Rakun, J., (2012). Programmable ultrasonic sensing system for targeted spraying in orchards. Sensors, ISSN 1424-8220, 11, pp. 15500-15519.

Stajnko, D.; Vindiš, P. \& Lakota, M. (2013). Newel approaches for targeted spraying in orchards. In: DAAAM International scientific book 2013, Katalinić, B. (Ed.), Tekic, Z. (Ed.), pp. 561-570, ISSN 1726-9687, Vienna: DAAAM International Vienna.

Stajnko, D.; Vindiš, P. \& Muršec, B. (2011). Automated system for targeted spraying in orchards by using RGB imaging. In: DAAAM International scientific book 2011, Katalinić, B. (Ed.), pp. 283-300, ISSN 1726-9687, Vienna: DAAAM International Vienna.

Walklate, P.J.; Cross, J.V.; Richardson, G.M.; Murray, R.A. \& Baker, D.E. (2002). Comparison of different spray volume deposition models using LIDAR measurements of apple orchards. Biosyst. Eng., ISSN 1537-5110 82 (3), 253-267. 